\title{
대형경유자동차의 $\mathrm{NO}_{2} / \mathrm{NO}_{x}$ 비율과 $\mathrm{NO}_{x}$ 배출특성에 관한 연구 A Study on $\mathrm{NO}_{2} / \mathrm{NO}_{x}$ Ratio and $\mathrm{NO}_{x}$ Emission Characteristics of Heavy-Duty Diesel Vehicles
}

\author{
정택호 · 김선문 · 문선희 · 홍희경 - 이승환 - 서석준 · 김정화 - 정성운 · 김인구 · 이종철 · 이종태 \\ Taek Ho Chung · Sun Moon Kim · Sun Hee Mun · Hee Kyoung Hong - Seoung Hwan Lee · \\ Seok Jun Seo · Joung Hwa Kim · Sung Woon Jung $\cdot$ In Gu Kim $\cdot$ Jong Chul Lee ${ }^{\dagger} \cdot$ Jong Tae Lee \\ 국립환경과학원 교통환경연구소 \\ Transportation Pollution Research Center, National Institute of Environmental Research
}

(Received March 29, 2019; Revised April 17, 2019; Accepted April 18, 2019)

\begin{abstract}
NO}_{\mathrm{x}}$ emitted from heavy-duty diesel vehicles has a high percentage of domestic emissions in Korea. It is known that the $\mathrm{NO}_{2}$ emission was polluted the atmospheric environments and was harmful to humans. Therefore, investigation on $\mathrm{NO}_{2} / \mathrm{NO}_{\mathrm{x}}$ Ratio and $\mathrm{NO}_{\mathrm{x}}$ Emission Characteristics of Heavy-Duty Diesel Vehicles were carried out. In this study, $\mathrm{NO}_{\mathrm{x}}$ emissions from heavy-duty trucks and buses were measured by chassis dynamometer for heavy-duty vehicle in real time. Also, $\mathrm{NO}_{2} / \mathrm{NO}_{\mathrm{x}}$ ratio and $\mathrm{NO}_{\mathrm{x}}$ emission characteristics were analyzed by emission analyzer according to various conditions. It is revealed that $\mathrm{NO}$ and $\mathrm{NO}_{2}$ concentrations were increased in the acceleration section from results of $\mathrm{NO}_{\mathrm{x}}$ concentration in real time. $\mathrm{The}_{\mathrm{NO}}$ emissions of heavy-duty trucks in test mode was confirmed a high level in order the average speed, but $\mathrm{NO}_{\mathrm{x}}$ emissions of heavy-duty buses were increased as the average speed increased. The $\mathrm{NO}_{2} / \mathrm{NO}_{\mathrm{x}}$ ratio of heavy duty trucks and buses was $0.7 \sim 1.0 \%$ and $7.7 \sim 7.8 \%$ at hot start engine condition. The results of this study will contribute to be used as basic data for the estimation of $\mathrm{NO}_{2}$ concentration in the roadside air monitoring network.
\end{abstract}

Key Words : Nitrogen oxide, Nitrogen dioxide, $\mathrm{NO}_{2} / \mathrm{NO}_{x}$ Ratio, Heavy-duty diesel vehicles

요약 : 대형경유자동차에서 배출되는 $\mathrm{NO}_{x}$ 는 국내 $\mathrm{NO}_{\mathrm{x}}$ 배출량 중 높은 비율을 차지하고 있으며, $\mathrm{NO}_{2}$ 는 인체에 유해하며 대 기환경을 오염시키는 물질로 알려져 있다. 본 연구에서는 대형경유트럭과 대형경유버스에서 배출되는 $\mathrm{NO}_{\mathrm{x}}$ 를 실시간으로 측 정하였으며, 다양한 조건에 따른 $\mathrm{NO}_{2} / \mathrm{NO}_{\mathrm{x}}$ 비율과 $\mathrm{NO}_{\mathrm{x}}$ 배출특성을 파악하였다. 실시간으로 $\mathrm{NO}_{\mathrm{x}}$ 의 농도를 측정한 결과 $\mathrm{NO}$ 와 $\mathrm{NO}_{2}$ 의 농도는 높은 출력을 요구하는 가속구간에서 증가하는 것으로 나타났다. 시험모드별 대형트럭의 $\mathrm{NO}_{\mathrm{x}}$ 배출량은 WHVC $>$ NIER 9>UDDS 순으로 낮은 평균속도에서 높게 배출되었다. 반면, 대형버스의 $\mathrm{NO}_{\mathrm{x}}$ 배출량은 평균속도가 증가할수록 높게 배출되는 것을 확인하였다. 엔진 상태에 따른 대형트럭과 버스의 $\mathrm{NO}_{\mathrm{x}}$ 배출량은 엔진 미가열조건에서 $23 \%, 78 \%$ 높게 배출되었다. 대형트럭과 대형버스의 $\mathrm{NO}_{2} / \mathrm{NO}_{\mathrm{x}}$ 비율은 엔진 가열조건에서 각각 $0.7 \sim 1.0 \%, 7.7 \sim 7.8 \%$ 로 확인되었다. 본 연구의 결과는 도로변대기측정망의 $\mathrm{NO}_{2}$ 농도 산정을 위한 기초자료로 활용될 것으로 기대한다.

주제어 : 질소산화물, 이산화질소, $\mathrm{NO}_{2} / \mathrm{NO}_{\mathrm{X}}$ 비율, 대형트럭, 대형버스

\section{1. 서 론}

국내에서는 승용차 뿐만 아니라 대형차 배출허용기준도 지속적으로 강화되어 선진국 수준으로 관리되고 있지만, 자동차로부터 배출되는 다양한 오염물질 중에 특히 질소산 화물 $(\mathrm{NOx})$ 은 여전히 도심지역의 대기환경을 오염시키는 주요 배출원으로 알려져 있다. ${ }^{1)}$ 2018년 국토교통부 자동차 등록대수에 의하면 국내 경유화물차의 자동차등록대수는 약 359만대로 매년 꾸준히 증가되고 있으며, 2017년 연도 별 평균 일교통량은 전체 차량 중에 트럭은 $26.0 \%$, 버스는 $2.6 \%$ 로 높은 비율을 차지하는 것으로 조사되었다. ${ }^{2)}$ 아울러 경유트럭의 경우는 연간주행거리가 승용차에 비하여 훨씬 높으며 버스의 경우 저속구간의 주된 주행으로 인하여 대 기오염물질 배출이 높은 것으로 알려져 있다.

2015년 국가 대기오염물질 배출량 중 도로이동오염원의 $\mathrm{NO}_{\mathrm{x}}$ 배출량은 전체 배출량의 약 $31.9 \%$ 로 배출기여율이
가장 높았으며, 특히 도로이동오염원 중 화물차와 버스의 $\mathrm{NO}_{\mathrm{x}}$ 배출량은 약 $65.2 \%$ 로 높은 비율을 나타냈다. ${ }^{3)}$ 또한 국내 주요 도시의 연평균 이산화질소 $\left(\mathrm{NO}_{2}\right)$ 농도는 자동차 배출허용기준이 강화됨에도 불구하고 90 년 이후 비슷한 수 준을 보였으며, 주로 자동차 등록대수 및 통행량이 많은 수 도권지역과 주요 도시에서 높은 것으로 알려져 있다. ${ }^{4)}$ 자 동차에서 배출되는 $\mathrm{NO}_{x}$ 는 대부분 일산화질소 $(\mathrm{NO})$ 와 $\mathrm{NO}_{2}$ 로 배출되며, $\mathrm{NO}$ 는 대기 중의 오존 및 휘발성 유기화합물 질 등과 산화반응하여 $\mathrm{NO}_{2}$ 로 전환된다. 그러나 도로변에 서는 이러한 산화반응이 일어나기 위한 시간이 충분하지 않아 $\mathrm{NO}_{2}$ 로의 전환이 제한될 수 있기 때문에, 자동차에서 1 차로 배출되는 $\mathrm{NO}_{2}$ 의 농도는 도로변 $\mathrm{NO}_{2}$ 농도에 직접적 인 영향을 준다. ${ }^{5)}$ 또한 자동차에서 배출되는 $\mathrm{NO}_{2}$ 는 인간의 폐기능 저하 및 암 위험을 증가시키는 등 인체 건강과 대 기환경에 심각한 피해를 주는 것으로 알려져 있다.)

선진국에서는 차대동력계, 이동식 배출가스 측정장비 등 
을 활용하여 자동차에서 1 차로 배출되는 $\mathrm{NO}_{2}$ 배출량과 $\mathrm{NO}_{2} / \mathrm{NO}_{\mathrm{X}}$ 비율을 측정하는 연구 ${ }^{7,8}$ 와 도로변과 터널의 대 기질 측정을 통해 $\mathrm{NO}_{2}$ 농도를 분석하는 연구, ${ }^{6}$ 통계모델을 이용하여 $\mathrm{NO}_{2}$ 농도를 예측하는 등의 다양한 연구가 진행 되고 있다. ${ }^{9-11)}$ 이에 본 연구에서는 국내 대형경유자동차 중 운행 중인 대형트럭과 대형버스를 대상으로 대형차대동 력계와 $\mathrm{NO}_{\mathrm{X}}$ 분석기를 이용하여 다양한 주행모드에서의 배 출가스를 측정 분석하였다. 측정된 배출가스를 통하여 차 량 및 주행모드별로 1 차로 배출되는 $\mathrm{NO}$ 와 $\mathrm{NO}_{2}$ 의 농도와 $\mathrm{NO}_{2} / \mathrm{NO}_{\mathrm{X}}$ 비율의 특성을 비교 분석하였다. 향후 본 연구의 분석결과를 통해 도로변대기측정망의 정확한 $\mathrm{NO}_{2}$ 의 농도 산정을 위한 기초자료로 활용하여 대기질 개선에 기여하고 자 한다.

\section{2. 실험방법 및 실험장치}

\section{1. 실험방법}

\subsection{1. 시험차량}

본 연구에서는 국내에서 판매되어 운행 중인 대형경유자 동차 중 점유율이 높은 Euro 5 배출허용기준을 만족하는 $6 \mathrm{~L}$ 급 대형트럭과 $13 \mathrm{~L}$ 급 대형버스 각각 1 대를 선정하였 다. 또한, 실제 도로를 주행할 때의 적재량을 고려하여, 대 형트럭은 최대 적재량의 $50 \%$, 대형버스는 최대승차인원의 $50 \%$ 의 무게를 적재하였다. 시험차량의 상세 제원은 Table 1 에 나타내었다.

\subsection{2. 시험모드}

다양한 시험모드에서 $\mathrm{NO}_{x}$ 의 배출가스 특성을 분석하기 위하여 시험모드는 국립환경과학원에서 개발한 국내 도로 주행패턴 중 NIER 9 모드와 국제 대형차 주행모드인 WHVC (World Harmonized Vehicle Cycle) 모드 및 UDDS(Urban Dynamometer Driving Schedule) 모드로 선정하였다. NIER 9 모드의 평균속도는 $34.4 \mathrm{~km} / \mathrm{h}$ 로 일반적으로 배출계수 산 정을 위해 사용되며 $W H V C$ 는 평균속도가 $41.3 \mathrm{~km} / \mathrm{h}$ 로 가장 높으며 국제적으로 널리 사용되는 모드이다. 또한 UDDS 는 대형차 도시 동력계 주행모드로 최대속도가 가장 높은 시험모드이다. 상세 시험모드의 주행거리 및 속도 등에 대 해서는 Table 2에 시간별 상세 주행패턴은 Fig. 1에 나타내 었다.

Table 1. Specification of test vehicles

\begin{tabular}{ccc}
\hline Vehicle & Truck & Bus \\
\hline \hline After treatment & SCR & DOC + pDPF \\
Displacement (cc) & 5,880 & 12,742 \\
GCW (kg) & 14,640 & 15,410 \\
Max Power (ps/rpm) & $260 / 2500$ & $430 / 1800$ \\
Emission Standard & Euro 5 & Euro 5 \\
\hline
\end{tabular}

Table 2. Specifications of test modes

\begin{tabular}{ccccc}
\hline $\begin{array}{c}\text { Test } \\
\text { mode }\end{array}$ & $\begin{array}{c}\text { Driving time } \\
(\mathrm{s})\end{array}$ & $\begin{array}{c}\text { Driving } \\
\text { distance } \\
(\mathrm{km})\end{array}$ & $\begin{array}{c}\text { Average } \\
\text { speed } \\
(\mathrm{km} / \mathrm{h})\end{array}$ & $\begin{array}{c}\text { Maximum } \\
\text { speed } \\
(\mathrm{km} / \mathrm{h})\end{array}$ \\
\hline \hline NIER 9 & 851 & 8.1 & 34.4 & 68.9 \\
WHVC & 1800 & 20.7 & 41.3 & 87.8 \\
UDDS & 1060 & 8.9 & 30.4 & 93.3 \\
\hline
\end{tabular}

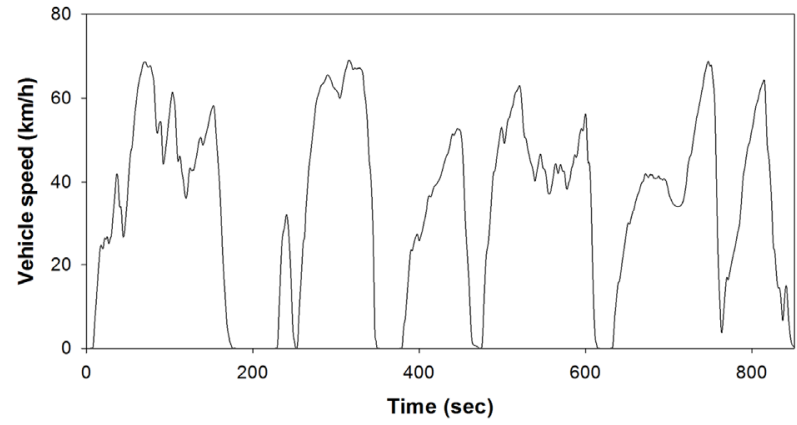

(a) NIER 9

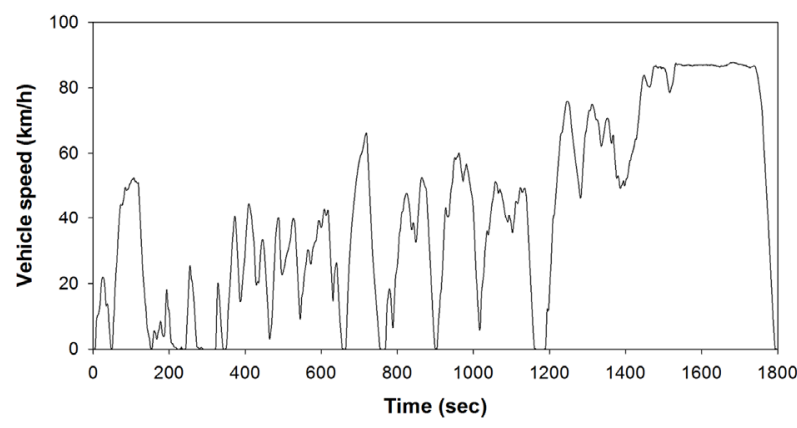

(b) WHVC

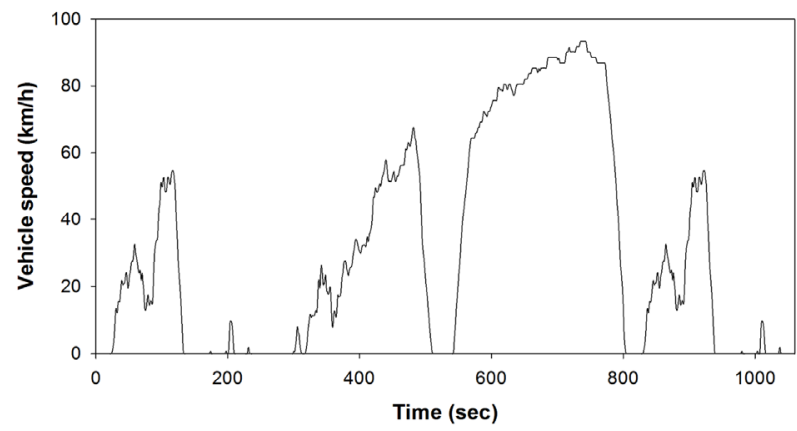

(c) UDDS

Fig. 1. Driving pattern of test modes.

\section{2. 실험장치}

\subsection{1. 배출가스 측정시스템}

배출가스 측정시스템은 차대동력계와 시료채취장치, 보 조운전장치, 희석터널, 입자상물질측정장치, 배출가스 분석 기 등으로 구성되어 있다. 대형차대동력계는 자동차가 실 제 도로를 주행 시 발생되는 구름저항 및 공기저항과 정지, 가속, 정속, 감속을 재현할 수 있는 장치이다. 시험차량이 동력계 롤러에서 설정된 시험모드를 주행 시, 자동차에서 배출되는 배기가스를 희석터널에서 희석공기와 혼합하여 


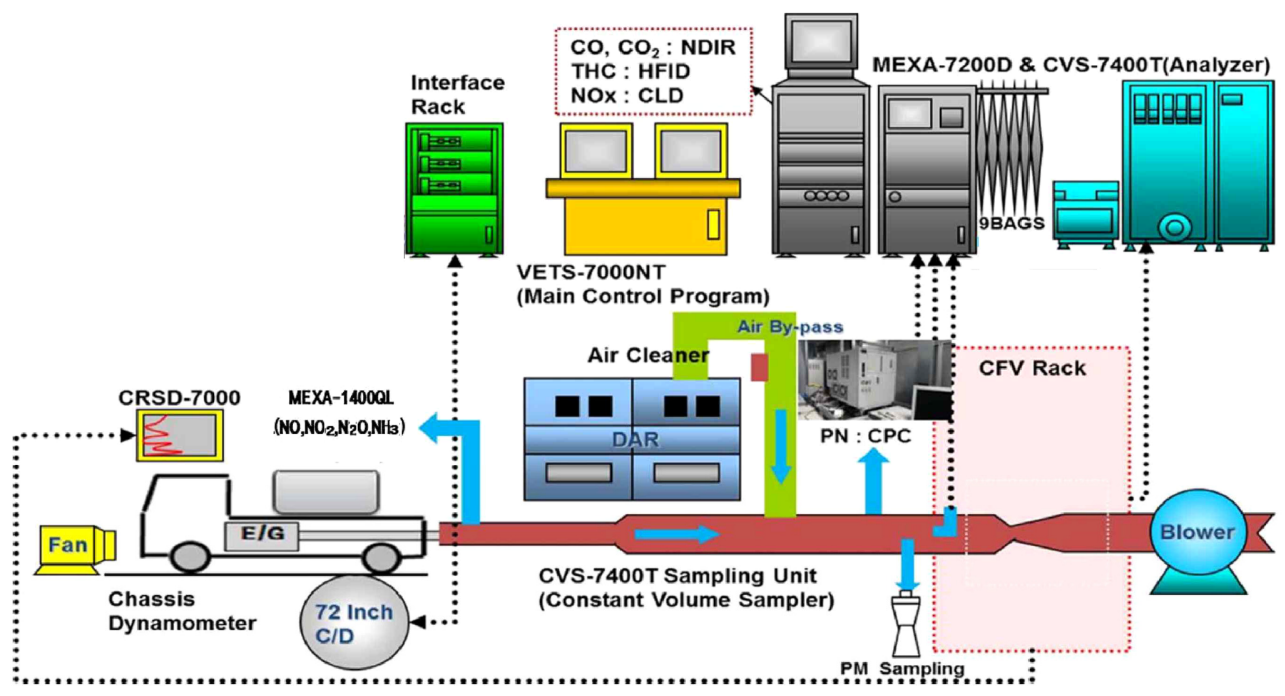

Fig. 2. Schematic diagram for exhaust emission test system.

정용량 시료채취장치(Constant Volume Sampler, CVS)로 유 입된다. 혼합된 가스의 일부를 $\mathrm{NO}_{\mathrm{X}}$ 분석기를 사용하여 분 석하였다. 시험장치 구성에 대한 상세 내용은 Fig. 2에 나 타내었다.

\subsection{2. $\mathrm{NO}_{\mathrm{x}}$ 분석기}

자동차 배출가스 중 $\mathrm{NO}_{\mathrm{X}}$ 를 $\mathrm{NO}$ 및 $\mathrm{NO}_{2}, \mathrm{~N}_{2} \mathrm{O}, \mathrm{NH}_{3}$ 로 분 류하여 실시간으로 측정할 수 있는 $\mathrm{NO}_{\mathrm{X}}$ 분석기(Horiba, MEXA-1400QL-NX)를 사용하여 본 연구를 수행하였다. 측 정방법은 양자 캐스케이드 레이저 광원과 정밀하게 조정된 광학 셀을 조합한 양자 캐스케이드 레이저 적외선 분광법 (Quantum Cascade Laser Infrared, QCL-IR)을 사용하며, 넓 은 범위에서 고감도로 저농도의 $\mathrm{NO}_{\mathrm{X}}$ 를 분석할 수 있다. 선 행연구에서 MEXA-1400QL-NX 분석기와 차대동력계 분석 기(Horiba, MEXA-7200H)의 $\mathrm{NO}_{\mathrm{X}}$ 배출량 측정결과를 비교 한 결과, 상관성이 높은 것으로 확인된 바 있다. ${ }^{7)}$ Table 3 에 $\mathrm{NO}_{\mathrm{X}}$ 분석기의 상세 제원을 보여주고 있다.

\section{3. 결과 및 고찰}

\section{1. $\mathrm{NO}_{\mathrm{x}}$ 배출특성}

본 연구에서는 다양한 주행모드에 따른 $\mathrm{NO}_{\mathrm{X}}$ 배출량을 실시간으로 취득하고 그 결과를 분석하였다. Fig. 3은 실시 간으로 측정한 대형트럭과 대형버스의 $\mathrm{NO}$ 와 $\mathrm{NO}_{2}$ 의 배출 농도를 나타내었으며, 모든 시험모드의 가속구간에서는 $\mathrm{NO}_{\mathrm{X}}$ 의 배출량이 증가하는 것을 확인하였다. 특히 가속 초기 구 간에서 급격히 증가하는 것을 볼 수 있는데 이는 가속을 할 경우 반적상태에서 순간적으로 부하가 걸리기 때문에 엔진의 높은 출력을 내기 위하여 흡입공기 대비 연료분사 량이 높아지게 된다. 따라서 연료분사량의 증가는 연소온 도를 높이기 때문에 $\mathrm{NO}_{\mathrm{X}}$ 배출량이 증가한 것으로 판단된 다. ${ }^{12)}$ 그에 비해 정속구간이나 감속구간에서는 낮은 $\mathrm{NO}_{\mathrm{X}}$
Table 3. Specification of $\mathrm{NO}_{x}$ Analyzer

\begin{tabular}{cc}
\hline Item & Specification \\
\hline \hline Components & $\mathrm{NO}, \mathrm{NO}_{2}, \mathrm{~N}_{2} \mathrm{O}, \mathrm{NH}_{3}$ \\
Principle & Quantum Cascade Laser \\
Sampling speed & $10 \mathrm{~Hz}$ \\
Flow rate & $8 \mathrm{~L} / \mathrm{min} \pm 1 \mathrm{~L} / \mathrm{min}$ \\
Sample line temperature & $113 \pm 66^{\circ} \mathrm{C}$ \\
Response time (t10-90) & $\mathrm{NO}, \mathrm{NO}_{2}, \mathrm{~N}_{2} \mathrm{O}:\langle 2 \mathrm{~s}$ \\
Span noise & $\mathrm{NH}_{3}:\langle 5 \mathrm{~s}$ \\
Zero / span drift & $\langle 2 \%$ full scale (FS) \\
\hline
\end{tabular}

배출량을 보이는 것으로 나타났다.

Fig. 4는 냉각수 온도가 안정화되도록 엔진을 충분히 예 열한 상태인 엔진 가열조건에서 배출되는 대형트럭의 $\mathrm{NO}_{\mathrm{X}}$ 평균농도 결과이다. Fig. 4에서 보는 바와 같이 시험모드의 평균 속도가 증가함에 따라 $\mathrm{NO}_{\mathrm{X}}$ 의 평균농도가 낮아지는 것을 볼 수 있는데, 이는 고속구간이 많은 구간에서 SCR 장치의 효율이 높은 것으로 판단된다. 이를 확인하기 위하 여 WHVC모드를 도심, 교외, 고속도로의 3구간으로 분류 하였다. 구간별 $\mathrm{NO}_{\mathrm{X}}$ 배출량은 상대적으로 가속과 감속 횟 수가 많은 도심과 교외 구간에서 높았으며, 평균속도가 높 은 고속도로 구간에서 낮아짐을 확인하였다. 이에 대한 선 행연구에서도 $\mathrm{SCR}$ 이 장착된 Euro 4, 5 트럭의 $\mathrm{NO}_{\mathrm{X}}$ 배출 량은 고속도로 구간에서 낮은 것으로 나타났다. ${ }^{13)}$

대형버스에 대한 $\mathrm{NO}_{\mathrm{x}}$ 배출량을 확인하기 위하여 동일한 시험모드에서 주행하고 측정하였다. Fig. 5는 엔진 가열조 건에서 배출되는 대형버스의 $\mathrm{NO}_{\mathrm{X}}$ 평균농도를 보여주고 있 으며, 대형버스의 경우는 대형트럭과 반대로 시험모드의 평균 속도가 증가할수록 높게 배출하는 경향을 보였다. 특히 WHVC모드에서 대형버스의 $\mathrm{NO}_{\mathrm{x}}$ 평균농도는 평균속도가 높은 고속도로 구간에서 높았다. 이는 대형버스의 경우는 


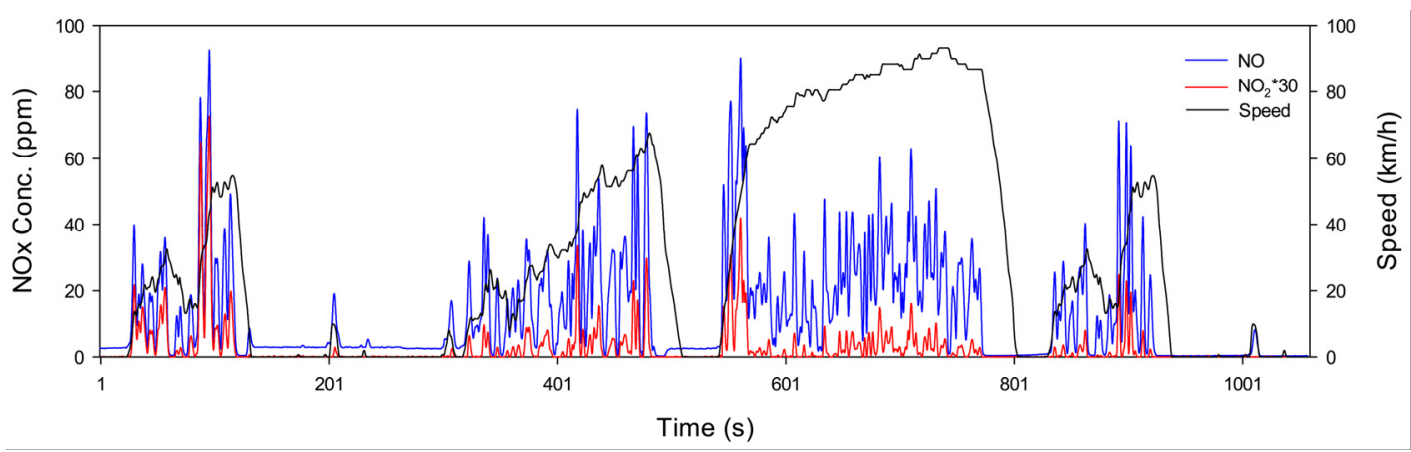

(a) UDDS (Truck)

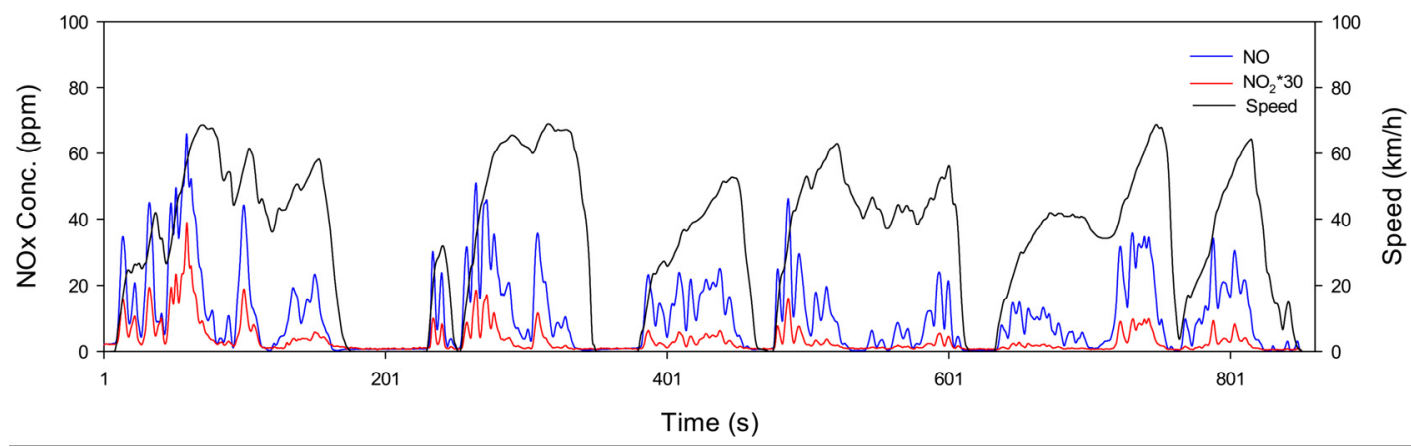

(b) NIER 9 (Truck)

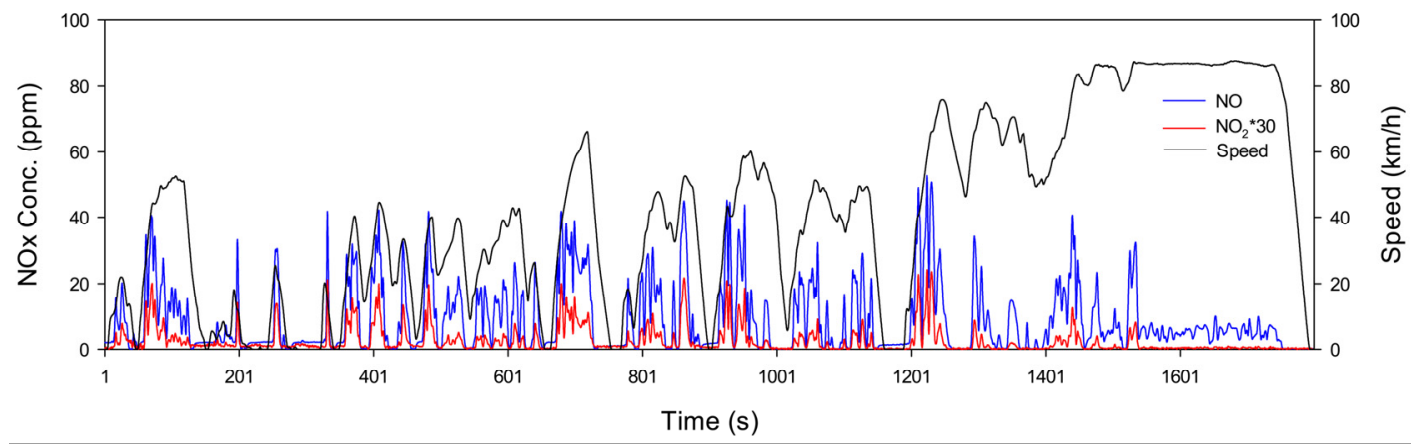

(c) WHVC (Truck)

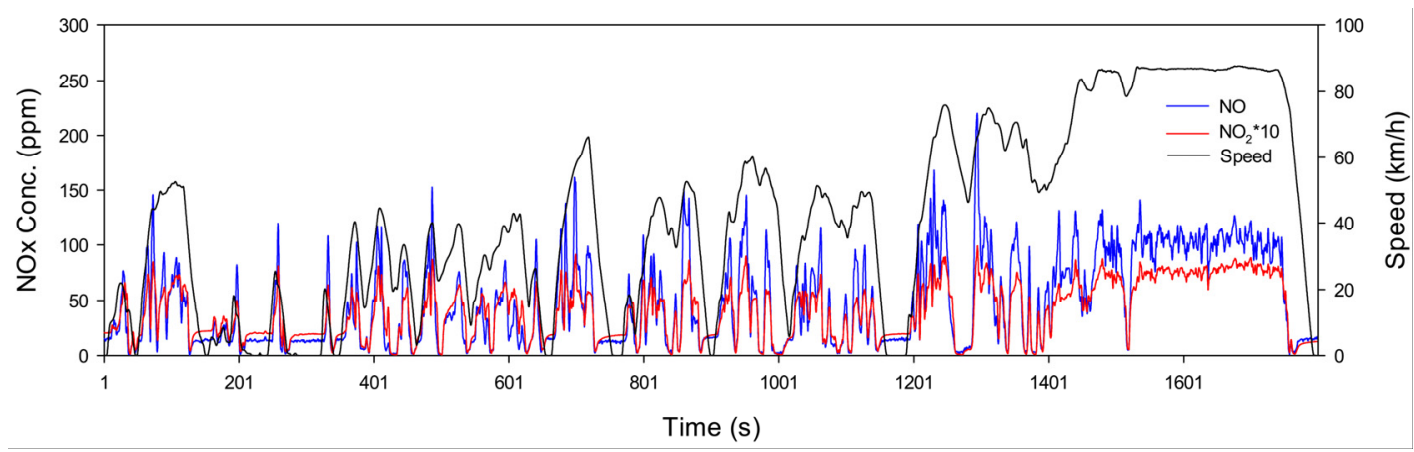

(d) WHVC (Bus)

Fig. 3. Real-time $\mathrm{NO}_{x}$ concentrations emitted from truck and bus.

$\mathrm{SCR}$ 저감장치가 없기 때문에 고속구간의 고부하 조건에서 발생되는 $\mathrm{NO}_{\mathrm{X}}$ 를 저감시키지 못하여 도심과 교외구간 대비 많이 생성된 것으로 판단된다.
열간 및 냉간 시 엔진상태에 따른 $\mathrm{NO}_{\mathrm{x}}$ 의 배출특성을 확 인하기 위하여 NIER 9 모드에서 엔진 가열조건과 미가열 조건의 $\mathrm{NO}_{\mathrm{X}}$ 배출량을 측정하였다. Fig. 6에 제시한 바와 


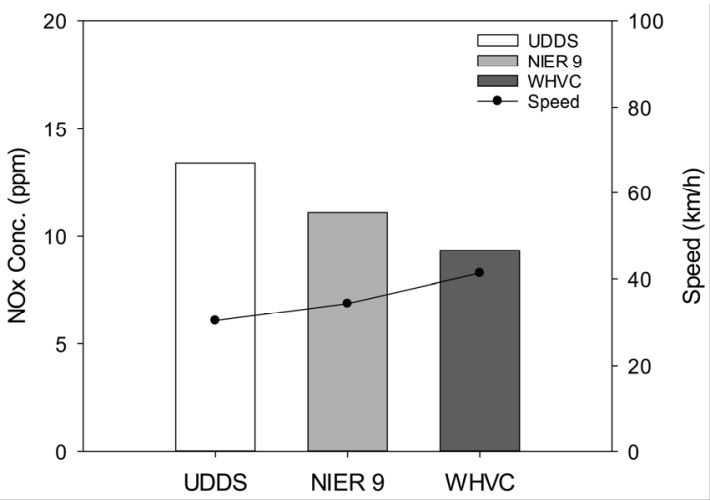

(a) Engine hot start condition under each mode

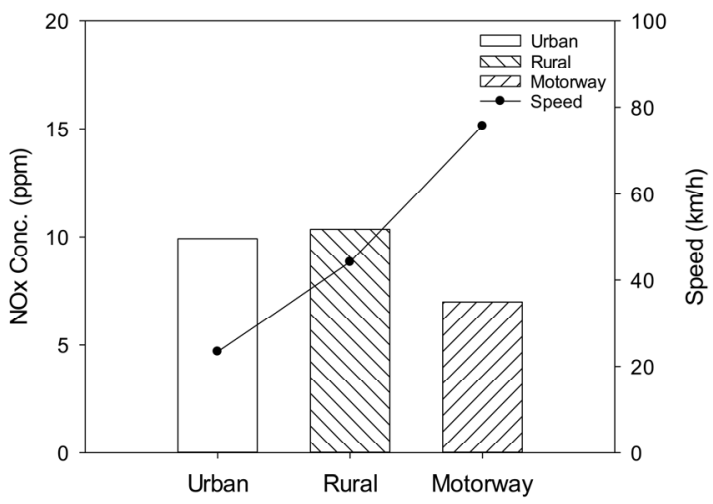

(b) Engine hot start condition under WHVC

Fig. 4. NOx concentrations of truck in engine hot start condition under each mode.

같이 대형트럭과 대형버스의 $\mathrm{NO}_{\mathrm{x}}$ 배출농도는 엔진 가열 조건 대비 엔진 미가열조건에서 각각 $23 \%, 78 \%$ 높게 배출 되었다. 이는 냉각수 온도가 낮은 엔진 미가열조건에서는 엔진과 후처리장치가 활성화되기 위한 예열 시간이 부족하 여 대형버스의 산화촉매(DOC) 장치가 원활히 작동이 되지 않으며, 저온에서 대형트럭의 SCR 요소수 분사 지연으로 $\mathrm{NO}_{\mathrm{x}}$ 배출농도가 높게 배출된 것으로 판단된다. ${ }^{6,14)}$

\section{2. $\mathrm{NO}_{2} / \mathrm{NO}_{x}$ 비율}

Table 4에는 시험모드에 대한 $\mathrm{NO}, \mathrm{NO}_{2}, \mathrm{NO}_{x}$ 의 농도와 $\mathrm{NO}_{2} / \mathrm{NO}_{\mathrm{X}}$ 비율을 나타내었다. Fig. 7 에 제시한 바와 같이 엔진 가열조건에서 대형트럭의 $\mathrm{NO}_{2} / \mathrm{NO}_{\mathrm{x}}$ 비율은 $0.7 \sim 1.0 \%$, 대형버스의 비율은 7.7 7.8\%로 시험모드의 변화에도 유사한 수준으로 확인되었다. 이를 통해 엔진 가열조건에서 $\mathrm{NO}_{2} /$ $\mathrm{NO}_{\mathrm{x}}$ 비율은 시험모드와 차종에 무관함을 알 수 있다. 하지만, 엔진 미가열조건에서는 대형트럭은 $2.70 \%$ 로 엔진가열조건 보다 증가하고 대형버스는 $5.99 \%$ 로 감소하는 특성을 보여 주었다. 또한 엔진상태에 따른 대형버스의 $\mathrm{NO}_{2} / \mathrm{NO}_{\mathrm{x}}$ 비율은 대형트럭보다 높은 것을 확인하였다. Carslaw et al. (2013) 의 연구에서도 원격감지기술을 이용하여 운행차를 대상으 로 도로변에서 $\mathrm{NO}_{2} / \mathrm{NO}_{\mathrm{x}}$ 비율을 측정한 결과, Euro 5 대형 트럭 대비 대형버스의 비율이 높은 것으로 보고하고 있다. ${ }^{8)}$

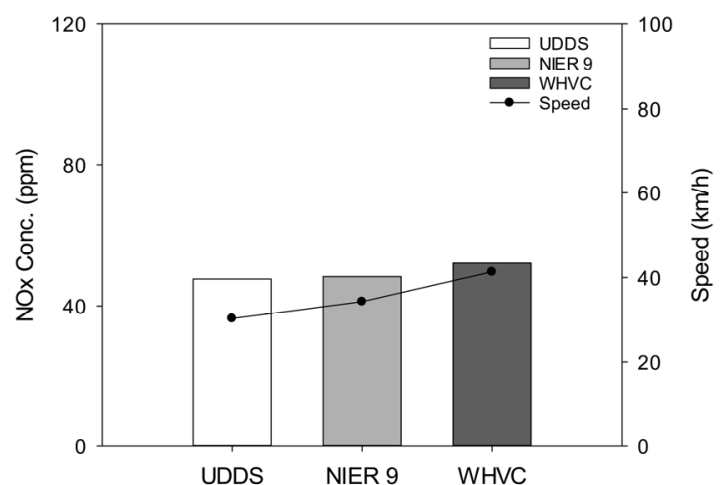

(a) Engine hot start condition under each mode

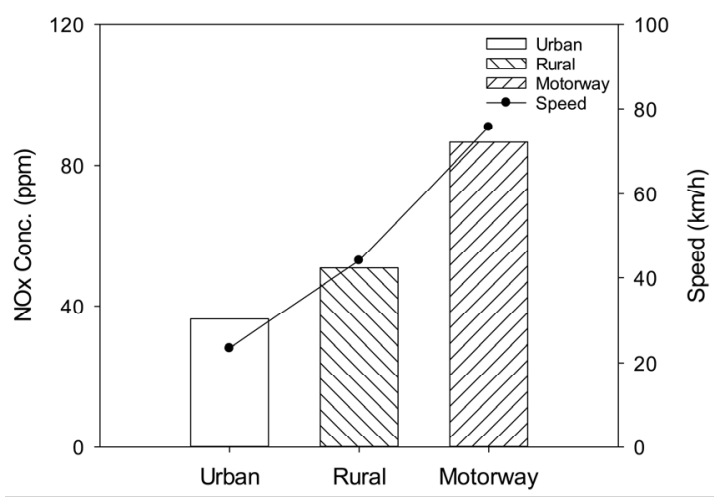

(b) Engine hot start condition under WHVC

Fig. 5. NOx concentrations of bus in engine hot start condition under each mode.

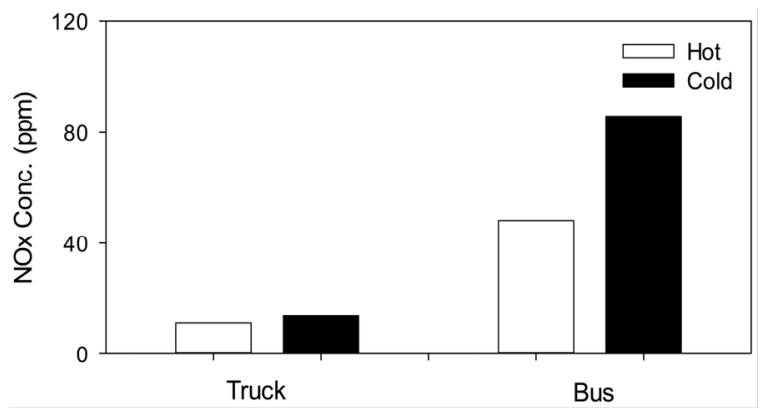

Fig. 6. $\mathrm{NO}_{\mathrm{x}}$ concentrations according to engine hot and cold start condition under NIER 9 mode.

Fig. 8은 NIER 9 모드에서 대형트럭과 대형버스의 엔진 가열조건과 엔진 미가열조건에 따른 $\mathrm{NO}_{2} / \mathrm{NO}_{\mathrm{X}}$ 비율 결과 이다. 대형트럭의 $\mathrm{NO}_{2} / \mathrm{NO}_{\mathrm{x}}$ 비율은 엔진 미가열조건 대비 엔진 가열조건에서 낮은 것으로 확인되었으며, 이는 엔진 가열조건에서 엔진과 후처리장치의 온도가 높기 때문에 SCR 장치가 활성화되어 $\mathrm{NO}$ 대비 $\mathrm{NO}_{2}$ 가 더 많이 저감된 것으로 사료된다. 반면 대형버스는 엔진 가열조건에서 높은 $\mathrm{NO}_{2} / \mathrm{NO}_{\mathrm{X}}$ 비율을 보였다. $\mathrm{NO}_{2}$ 는 배출가스 온도가 약 $350^{\circ} \mathrm{C}$ 에서 $\mathrm{DOC}$ 또는 DPF 촉매와 반응하여 생성되기 때문에, ${ }^{15,16)}$ 배출가스 온도가 낮은 엔진 미가열조건에서의 $\mathrm{NO}_{2} / \mathrm{NO}_{\mathrm{X}}$ 비율은 낮 은 것으로 판단된다. 
Table 4. NOx concentrations according to test modes

\begin{tabular}{|c|c|c|c|c|c|}
\hline & \multirow{3}{*}{ Test mode } & \multicolumn{4}{|c|}{ Components } \\
\hline & & NO & $\mathrm{NO}_{2}$ & $\mathrm{NOx}$ & $\mathrm{NO}_{2} / \mathrm{NO}$ \\
\hline & & $\mathrm{ppm}$ & ppm & ppm & $\%$ \\
\hline \multirow{4}{*}{ Truck } & NIER 9 cold start & $13.04 \pm 1.09$ & $0.37 \pm 0.03$ & $13.68 \pm 1.10$ & 2.70 \\
\hline & NIER 9 hot start & $10.65 \pm 0.63$ & $0.11 \pm 0.03$ & $11.07 \pm 0.66$ & 0.99 \\
\hline & WHVC hot start & $9.00 \pm 0.21$ & $0.08 \pm 0.02$ & $9.33 \pm 0.23$ & 0.86 \\
\hline & UDDS hot start & $13.02 \pm 0.60$ & $0.09 \pm 0.03$ & $13.40 \pm 0.63$ & 0.67 \\
\hline \multirow{4}{*}{ Bus } & NIER 9 cold start & $80.53 \pm 3.33$ & $5.15 \pm 0.34$ & $85.96 \pm 3.62$ & 5.99 \\
\hline & NIER 9 hot start & $44.20 \pm 3.49$ & $3.74 \pm 0.20$ & $48.29 \pm 3.64$ & 7.74 \\
\hline & WHVC hot start & $47.78 \pm 2.50$ & $3.99 \pm 0.23$ & $52.10 \pm 2.71$ & 7.66 \\
\hline & UDDS hot start & $43.49 \pm 1.47$ & $3.73 \pm 0.19$ & $47.57 \pm 1.31$ & 7.84 \\
\hline
\end{tabular}

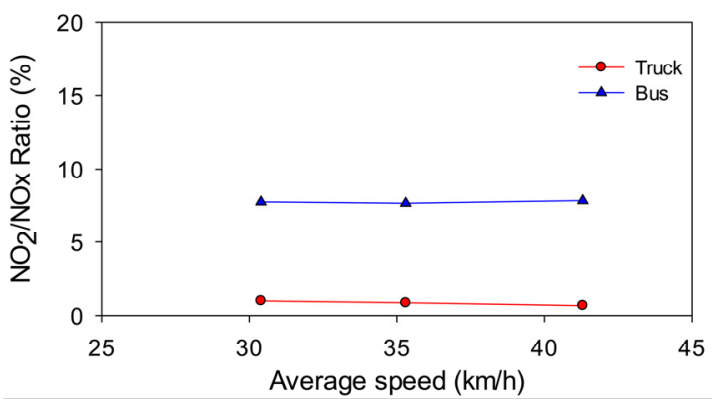

Fig. 7. $\mathrm{NO}_{2} / \mathrm{NO}_{x}$ ratio in engine hot start condition.

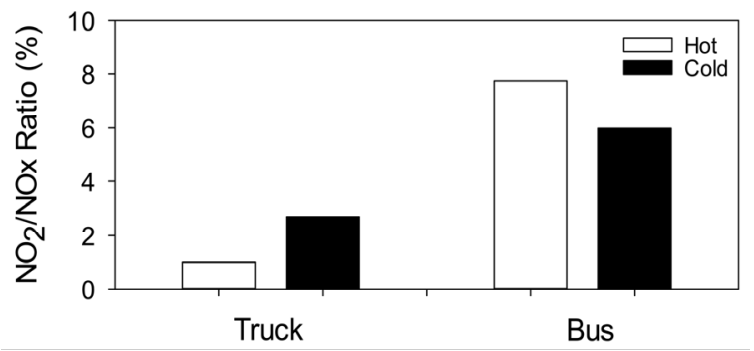

Fig. 8. $\mathrm{NO}_{2} / \mathrm{NO}$ x ratio according to engine hot and cold start condition under NIER 9 mode.

\section{4. 결 론}

본 연구에서는 대형경유트럭과 대형경유버스에서 배출되 는 $\mathrm{NO}_{\mathrm{x}}$ 의 배출특성을 분석하였으며, 다음과 같은 결론을 얻을 수 있었다.

1) 실시간으로 $\mathrm{NO}_{\mathrm{X}}$ 의 농도를 측정한 결과 $\mathrm{NO}$ 와 $\mathrm{NO}_{2}$ 의 농 도는 높은 출력을 요구하는 가속구간에서 증가하는 것 을 확인하였다.

2) 대형트럭의 $\mathrm{NO}_{\mathrm{X}}$ 배출량은 평균속도가 높은 WHVC모드 와 $\mathrm{WHVC}$ 의 고속도로 구간에서 낮게 배출되어 고속구 간에서 $\mathrm{SCR}$ 장치가 활성화된 것으로 판단된다. 반면 대 형버스의 $\mathrm{NO}_{\mathrm{X}}$ 배출량은 평균속도가 증가할수록 높게 배출되는 것을 확인하였다.

3) 엔진 상태에 따른 대형트럭과 대형버스의 $\mathrm{NO}_{\mathrm{X}}$ 배출량은 엔진 미가열조건에서 $23 \%, 78 \%$ 높게 배출되는 것으로 확인되었으며, 냉각수 온도가 낮은 엔진 미가열조건에 서 엔진과 후처리장치가 활성화되기 위한 예열 시간이
부족하기 때문으로 판단된다.

4) 엔진 가열조건에서 대형트럭과 대형버스의 $\mathrm{NO}_{2} / \mathrm{NO}_{\mathrm{X}}$ 비 율은 각각 $0.7 \sim 1.0 \%, 7.7 \sim 7.8 \%$ 로 확인되었다. 하지만, 엔진 미가열조건에서의 대형트럭과 대형버스 $\mathrm{NO}_{2} / \mathrm{NO}_{\mathrm{X}}$ 비율은 상반되는 것으로 나타났다.

5) 본 연구의 결과는 도로변대기측정망의 $\mathrm{NO}_{2}$ 농도 산정 및 대기오염 저감정책을 위한 기초자료로 활용될 것으 로 기대한다.

\section{Acknowledgement}

본 논문은 환경부의 재원으로 국립환경과학원의 지원을 받아 수행하였습니다(NIER-2017-01-01-078).

KSEE

\section{Reference}

1. Lee, T. W., Kim, J. Y., Park, J. H., Jeon, S. Z., Lee, J. T. and Kim, J. S., "Influence of Driving Routes and Seasonal Conditions to Real-driving NOX Emissions from Light Diesel Vehicles," Trans. of KSAE., 22(1), 148 156(2014).

2. Ministry of Land, Infrastructure and Transport, "Annual Traffic Volume Report 2017," Ministry of Land, Infrastructure and Transport, (2018).

3. National Institute of Environmental Research, "National Air Pollutants Emission 2015," National Institute of Environmental Research, (2018).

4. National Institute of Environmental Research, "Annual Report of Air Quality in Korea 2017," National Institute of Environmental Research, (2018).

5. O'Driscoll, R., ApSimon, H. M., Oxley, T., Molden, N., Stettler, M. E. J. and Thiyagarajah, A., "A Portable Emissions Measurement System (PEMS) study of $\mathrm{NO}_{\mathrm{X}}$ and primary $\mathrm{NO}_{2}$ emissions from Euro 6 diesel passenger cars and comparison with COPERT emission factors," Atmos Environ., 145, 81 91(2016).

6. Matthaios, V. N., Kramer, L. J., Sommariva, R., Pope, F. D. and Bloss, W. J., "Investigation of vehicle cold start primary $\mathrm{NO}_{2}$ emissions inferred from ambient monitoring 
data in the UK and their implications for urban air quality," Atmos Environ., 199, 402 414(2019).

7. Kim, S. M., Kim, J. H., Jung, S. W., Sung, K. J., Kim, J. S. and Kim, I. G., "Experimental Study on the $\mathrm{NO}_{2} / \mathrm{NO}_{\mathrm{X}}$ Ratio from Exhaust of Diesel Vehicles by Chassis Dynamometer," Trans. of Korean Hydrogen and New Energy Society, 28(2), 220 224(2017).

8. Carslaw, D. C. and Tyler, G. R., "New insights from comprehensive on-road measurements of $\mathrm{NO}_{\mathrm{X}}, \mathrm{NO}_{2}$ and $\mathrm{NH}_{3}$ from vehicle emission remote sensing in London, UK," Atmos Environ., 81, 339 347(2013).

9. Carslaw, D. C., "Evidence of an increasing $\mathrm{NO}_{2} / \mathrm{NO}_{\mathrm{X}}$ emissions ratio from road traffic emissions," Atmos Environ., 39, 4793 4802(2005).

10. Anttila, P., Tuovinen, J. P. and Niemi, J. V., "Primary $\mathrm{NO}_{2}$ emissions and their role in the development of $\mathrm{NO}_{2}$ concentrations in a traffic environment," Atmos Environ., 45, 986 992(2011).

11. Velders, G. J. M., Geilenkirchen, G. P. and Lange, R. D., "Higher than expected $\mathrm{NO}_{\mathrm{X}}$ emission from trucks may affect attainability of $\mathrm{NO}_{2}$ limit values in the Netherlands,"
Atmos Environ., 45, 3025 3033(2011).

12. Ko, J. Y., Jin, D. Y., Jang, W. W., Myung, C. L., Kwon, S. I. and Park, S. S., "Comparative investigation of $\mathrm{NO}_{\mathrm{X}}$ emission characteristics from a Euro 6-compliant diesel passenger car over the NEDC and WLTC at various ambient temperatures," Appl Energy., 187, 652 662(2017).

13. Kamakaté, F. and Lowell, D., "Urban off-cycle $\mathrm{NO}_{\mathrm{x}}$ emissions from Euro IV/V trucks and buses," ICCT, White Paper., 18, (2012).

14. Park, Y. J., Hong, W. K., Ka, J. G., Cho, Y. S., Joo, J. G. and Kim, H. O., "A Study on $\mathrm{NO}_{\mathrm{X}}$ Reduction in a Light Duty Diesel Vehicle Equipped with a SCR Catalyst," Trans. of KSAE., 19(5), 118 124(2011).

15. He, C., Li, J., Ma, Z., Tan, J. and Zhao, L., "High $\mathrm{NO}_{2} /$ $\mathrm{NO}_{\mathrm{X}}$ emissions downstream of the catalytic diesel particulate filter: An influencing factor study," J. Environ Sci., 35, 55 61(2015).

16. Benajes, J., López, J. J., Novella, R. and Redón, P., "Comprehensive modeling study analyzing the insights of the $\mathrm{NO}-\mathrm{NO}_{2}$ conversion process in current diesel engines," Energy Convers Manag., 84, 691 700(2014). 